07;09

\title{
ИК-люминесценция $\alpha-\mathrm{Al}_{2} \mathrm{O}_{3-\delta}$ при $4-300 \mathrm{~K}$
}

() М.Н. Сарычев ${ }^{1}$, И.И. Мильман ${ }^{1, \uparrow}$, А.И. Сюрдо ${ }^{2}$, Р.М. Абашев ${ }^{1}$, В.С. Воинов ${ }^{1}$

${ }^{1}$ Уральский федеральный университет им. Б.Н. Ельцина, Екатеринбург, Россия

${ }^{2}$ Институт промышленной экологии УрО РАН, Екатеринбург, Россия

๑E-mail: i.i.milman@urfu.ru

Поступило в Редакцию 16 апреля 2018 г.

Установлено, что в анионодефицитных кристаллах корунда $\left(\alpha-\mathrm{Al}_{2} \mathrm{O}_{3-\delta}\right)$ с помощью специальной термооптической обработки возможно преобразование простых центров окраски $F^{+}$- и $F$-типа (анионные вакансии с одним или двумя электронами) в сложные центры, в том числе дивакансионные $F_{2}$-типа. У таких кристаллов при гелиевых температурах в ближней ИК-области зарегистрирована тонкая структура полос фотолюминесценции сложных центров как известной, так и неизвестной природы. При их сравнении с подобными полосами фотолюминесценции в нейтронно-облученных образцах $\alpha-\mathrm{Al}_{2} \mathrm{O}_{3}$ исходно стехиометрического состава обнаружено полное сходство, что указывает на возможность нерадиационного создания сложных центров в $\alpha-\mathrm{Al}_{2} \mathrm{O}_{3}$.

DOI: $10.21883 /$ PJTF.2018.22.46924.17332

Люминесценция кристаллов $\alpha-\mathrm{Al}_{2} \mathrm{O}_{3}$ и материалов на его основе, связанная с собственными и примесными дефектами решетки, образующими центры окраски (ЦО), используется для создания активных элементов квантовой электроники, элементов лазерных устройств и силовой оптики, детекторов ионизирующих излучений $[1,2]$.

Исторически первым и до сих пор остающимся одним из эффективных способов создания ЦО в решетке совершенных кристаллов $\alpha-\mathrm{Al}_{2} \mathrm{O}_{3}$ является облучение нейтронами с флюенсами от $10^{13}$ до $10^{18} \mathrm{n} / \mathrm{cm}^{2}$, ускоренными электронами, протонами, ионами легких и тяжелых элементов [3-7]. Как правило, обнаружение и установление природы ЦО осуществляется по данным оптического поглощения (ОП), фотолюминесценции (ФЛ), электронного парамагнитного резонанса, позитрон-электронной аннигиляции. На основе результатов исследований свойств ЦО в радиационно-окрашенных кристаллах $\alpha-\mathrm{Al}_{2} \mathrm{O}_{3}$ 
созданы модельные представления о природе решеточных дефектов, основой которых являются кислородные вакансии, заполненные одним $\left(F^{+}\right.$-центры) или двумя ( $F$-центры) электронами, а также их комплексы друг с другом и с интерстициалами алюминия $\left(\mathrm{Al}_{i}\right)$ в различных зарядовых состояниях: $\mathrm{Al}_{i}^{+}-, F_{2}^{+}-, F_{2}^{2+}$-центры [3-7]. Созданные модели характеризуются относительной изученностью свойств простых и сложных ЦО радиационного происхождения в ближней ультрафиолетовой и видимой областях оптического спектра. В этих работах приведены современные представления о строении ЦО в кристаллах $\alpha-\mathrm{Al}_{2} \mathrm{O}_{3}$ и их основные спектральные характеристики: максимумы и полуширины полос ОП и ФЛ, поляризационные отношения, время жизни в возбужденном состоянии, измеренные при комнатной и низкой температурах. Часто для интерпретации результатов исследований используют зонную схему $\alpha-\mathrm{Al}_{2} \mathrm{O}_{3}$, располагая в запрещенной зоне энергетические уровни сложных ЦО в различных зарядовых состояниях с указанием энергий возбуждения, межуровневых переходов, сопровождаемых люминесценцией (см., например, [3]). Вместе с тем в имеющихся моделях [3] энергетических уровней сложных ЦО в $\alpha-\mathrm{Al}_{2} \mathrm{O}_{3}$ не отражена их способность излучать в ближней инфракрасной (ИК) области, наблюдавшаяся экспериментально в [8-12].

Особенностью ЦО, описанных в литературе, является то, что в результате облучения кристаллов $\alpha-\mathrm{Al}_{2} \mathrm{O}_{3}$ различными видами корпускулярных излучений высоких энергий образуются преимущественно простые ЦО $\left(F, F^{+}\right)$. Для преобразования их в сложные $\left(\mathrm{Al}_{i}^{+}, F_{2}^{+}\right.$, $F_{2}^{2+}$ ) требуется дополнительная термообработка облученных кристаллов при $600-770 \mathrm{~K}$ в течение определенного времени. Однако имеющиеся данные $[13,14]$ предполагают возможность создания сложных ЦО с междоузельным алюминием (ЦО $\mathrm{Al}_{i}$-типа) как при выращивании анионодефицитных кристаллов корунда, так и при их специальной термооптической обработке (ТОО).

Мотивацией настоящей работы послужило также то, что, согласно современным трендам, для создания элементов памяти и силовой оптики (активные и спектросмещающие элементы) интенсивно исследуются кристаллы $\alpha-\mathrm{Al}_{2} \mathrm{O}_{3}$ с собственными дефектами без специально введенных примесей, особенно дорогостоящих редкоземельных элементов $[9,10,12,15]$. Поэтому целью работы является изучение возможности нерадиационного создания сложных центров окраски в $\alpha-\mathrm{Al}_{2} \mathrm{O}_{3}$, люминесцирующих в ближней ИК-области оптического спектра.

Письма в ЖТФ, 2018, том 44, вып. 22 
Объектами исследования служили номинально чистые анионодефицитные монокристаллы корунда или $\alpha-\mathrm{Al}_{2} \mathrm{O}_{3-\delta}$, дефицит кислорода в которых создавался при их выращивании в восстановительных условиях: вакуум, присутствие углерода. Концентрация $F$-центров в исследуемых кристаллах составляла $\sim 10^{17} \mathrm{~cm}^{-3}$, а $F^{+}$-центров $10^{16} \mathrm{~cm}^{-3}$ [14]. Неожиданным результатом исследований оказалось то, что при определенных режимах ТОО кристаллов $\alpha-\mathrm{Al}_{2} \mathrm{O}_{3-\delta}$ происходит преобразование простых ЦО $F$-типа в широкий спектр сложных ЦО, и не только в ЦО $\mathrm{Al}_{i}$-типа. Такая ТОО заключалась в облучении кристаллов $\alpha-\mathrm{Al}_{2} \mathrm{O}_{3-\delta}$, нагретых до $1020-1070 \mathrm{~K}$, излучением ртутной лампы ДРШ-250 в течение 10-20 min. Качественные и количественные изменения ЦО в процессе ТОО наблюдались по спектрам ОП и ФЛ. Для сравнения, сопоставления и идентификации сложных ЦО при тех же условиях измерялись спектры ОП и ФЛ для номинально чистых стехиометрических образцов $\alpha-\mathrm{Al}_{2} \mathrm{O}_{3}$, облученных реакторными нейтронами флюенсом $10^{17} \mathrm{n} / \mathrm{cm}^{2}$ и термообработанных при $700 \mathrm{~K}$ в течение $10 \mathrm{~min}$. Спектры ОП измерялись при $T=295 \mathrm{~K}$ на спектрофотометре Cary 60. ФЛ и ее спектры исследовались при $T=4-300 \mathrm{~K}$ с использованием оптического гелиевого криостата Janis, работающего по циклу Гиффорда-МакМагона. В качестве источников возбуждения фотолюминесценции использовались ксеноновая лампа ДКсШ-150 с монохроматором MSD-1 и полупроводниковые лазеры непрерывного действия с длинами волн 450 и $660 \mathrm{~nm}$. Люминесценция в областях 200-900 и 600-1700 nm регистрировалась соответственно ФЭУ Hamamatsu R6356 и InGaAs-фотодиодом Hamamatsu G10899-02K, которые размещались на выходной щели монохроматора MDR-23, имеющей спектральную ширину $0.5 \mathrm{~nm}$.

Измерения спектров ОП показали, что ТОО приводит как к перераспределению концентраций простых $F$ - и $F^{+}$-центров, так и к появлению сложных $\mathrm{Al}_{i}^{+}-, F_{2}$-типа. При этом оказалось, что эффективность преобразования ЦО зависела от режимов ТОО: температуры, времени и интенсивности оптического излучения. На рис. 1 приведены спектры ОП образца $\alpha-\mathrm{Al}_{2} \mathrm{O}_{3-\delta}$ до (кривая 1) и после (кривая 2) проведения ТОО при $T=1070 \mathrm{~K}$ и $t=10 \mathrm{~min}$. Здесь же показан спектр ОП кристалла $\alpha-\mathrm{Al}_{2} \mathrm{O}_{3}$, облученного нейтронами (кривая 3). Следует отметить, что нагрев образцов $\alpha-\mathrm{Al}_{2} \mathrm{O}_{3-\delta}$ в тех же температурных и временны́х условиях, что и при проведении ТОО, но без оптического облучения не приводит к изменению спектра ОП исходных образцов 


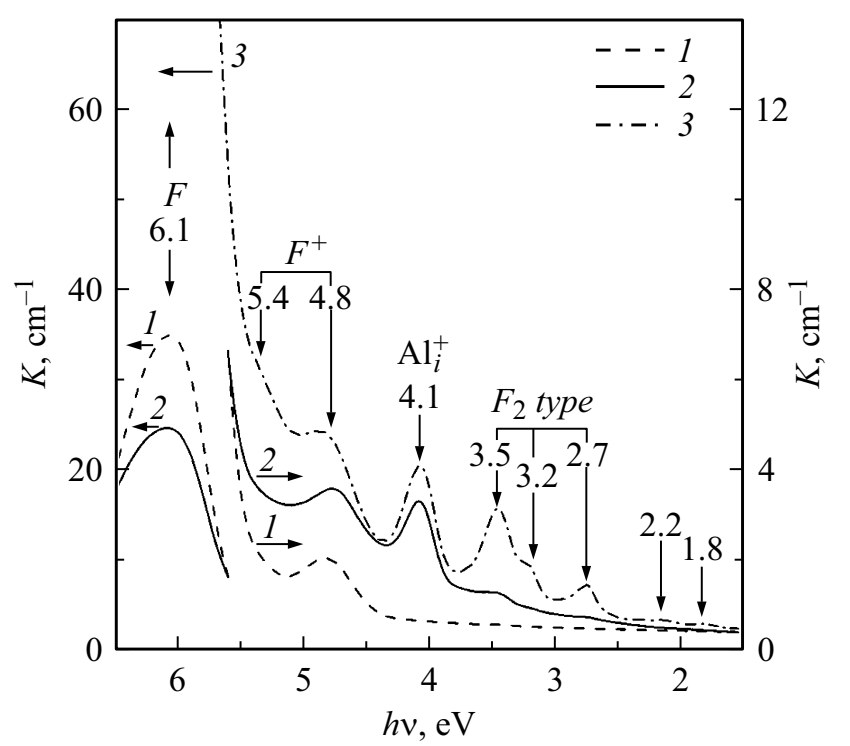

Pис. 1. Спектры оптического поглощения анионодефицитного образца $\alpha-\mathrm{Al}_{2} \mathrm{O}_{3-\delta}$ до (1) и после (2) ТОО, а также стехиометрического образца $\alpha-\mathrm{Al}_{2} \mathrm{O}_{3}$, облученного нейтронами флюенсом $10^{17} \mathrm{n} / \mathrm{cm}^{2}$ и отожженного при $700 \mathrm{~K}$ в течение $10 \mathrm{~min}(3)$.

$\alpha-\mathrm{Al}_{2} \mathrm{O}_{3-\delta}$, т.е. сложные центры не образуются. Получено также, что по сравнению со сложными ЦО, образованными в $\alpha-\mathrm{Al}_{2} \mathrm{O}_{3}$ нейтронным облучением, подобные ЦО, образованные в результате ТОО образцов $\alpha-\mathrm{Al}_{2} \mathrm{O}_{3-\delta}$, являются более термостабильными. Они отжигаются при $T \geqslant 950-1000 \mathrm{~K}$, что на $150-200 \mathrm{~K}$ больше, чем в случае нейтроннооблученных образцов $\alpha-\mathrm{Al}_{2} \mathrm{O}_{3}$.

Как видно из рис. 1 , результатом ТОО образцов $\alpha-\mathrm{Al}_{2} \mathrm{O}_{3-\delta}$ явилось снижение интенсивностей поглощения $F$ - и $F^{+}$-центров, а также появление новых полос ОП с максимумами $h v_{m}$ при 4.1, 3.5, 3.2 и $2.7 \mathrm{eV}$, аналогичных измеренным в нейтронно-облученных образцах. В последних также можно дополнительно наблюдать полосы ОП с $h v_{m}$ при 2.2 и $1.8 \mathrm{eV}$. Результаты сравнения спектров ОП образцов, облученных нейтронами и прошедших ТОО, свидетельствуют о создании сложных ЦО в кристаллах $\alpha-\mathrm{Al}_{2} \mathrm{O}_{3-\delta}$ без применения радиационных технологий.

Письма в ЖТФ, 2018, том 44, вып. 22 


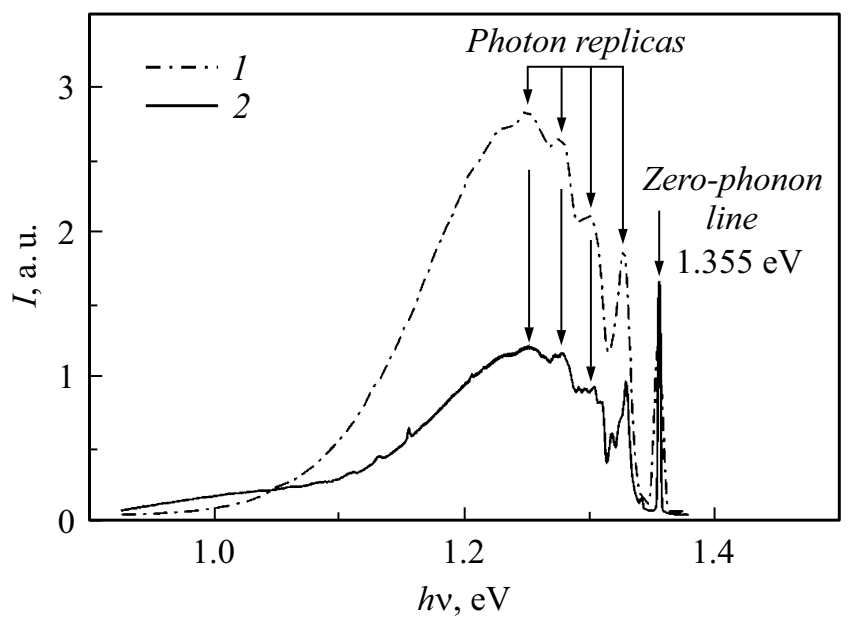

Рис. 2. Спектры фотолюминесценции, измеренные при $h v_{e x}=2.75 \mathrm{eV}$ и $T=8 \mathrm{~K}$ для нейтронно-облученного образца $\alpha-\mathrm{Al}_{2} \mathrm{O}_{3}(1)$ и для прошедшего TOO образца $\alpha-\mathrm{Al}_{2} \mathrm{O}_{3-\delta}$ (2).

Установление детальных механизмов преобразования простых ЦО в сложные с помощью ТОО нуждается в самостоятельных исследованиях. По предварительным данным, описанным в работах [14,16], можно предположить, что их основу составляют фотоиндуцированная ионизация, усиленная термическим возбуждением простых центров, их диффузионная подвижность при повышенной температуре и агломерация в сложные дефектные комплексы.

Основным подтверждением идентичности природы сложных ЦО, созданных ТОО в $\alpha-\mathrm{Al}_{2} \mathrm{O}_{3-\delta}$ и нейтронным облучением в $\alpha-\mathrm{Al}_{2} \mathrm{O}_{3}$, служат результаты измерений ФЛ у некоторых из них в ближней ИК-области. Измерения ФЛ для обоих типов образцов проведены в одинаковых условиях при $T=4-300 \mathrm{~K}$. Для возбуждения люминесценции одного из типов $F_{2}$-центров, поглощающих вблизи $2.7 \mathrm{eV}$ (рис. 1), использовалось лазерное излучение с длиной волны $450 \mathrm{~nm}\left(h v_{e x}=2.75 \mathrm{eV}\right)$. Видно (рис. 2), что полученные таким образом спектры ФЛ близки для образцов, подвергнутых нейтронному облучению и ТОО (кривые 1 и 2 соответственно). Более того, при низких температурах (как на рис. 2)

Письма в ЖТФ, 2018, том 44, вып. 22 


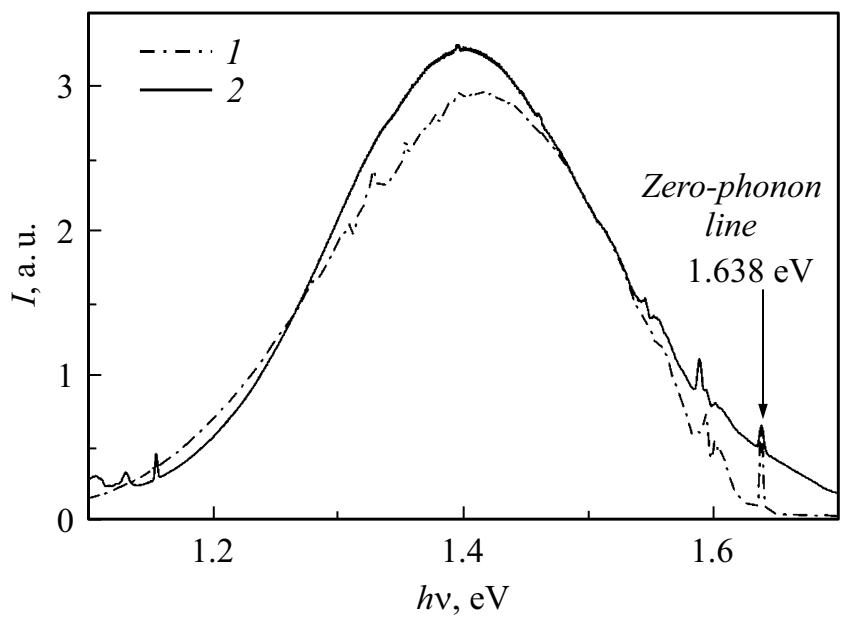

Рис. 3. Спектры фотолюминесценции, измеренные при $h v_{e x}=1.88 \mathrm{eV}$ и $T=8 \mathrm{~K}$ для нейтронно-облученного образца $\alpha-\mathrm{Al}_{2} \mathrm{O}_{3}(1)$ и для прошедшего ТОО образца $\alpha-\mathrm{Al}_{2} \mathrm{O}_{3-\delta}(2)$.

у полос ФЛ появляется тонкая структура с хорошо совпадающими бесфонными линиями (zero-phonon line) при $1.355 \mathrm{eV}$ и фононными повторениями при 1.328, 1.303 и $1.278 \mathrm{eV}$. Сходная картина наблюдается в спектрах ФЛ тех же образцов при лазерном возбуждении с длиной волны $660 \mathrm{~nm}\left(h v_{e x}=1.88 \mathrm{eV}\right)$, что близко к максимуму полосы ОП при $1.8 \mathrm{eV}$ пока не идентифицированных ЦО (рис. 3). Полосы ФЛ с максимумом при $1.49 \mathrm{eV}$ у облученного нейтронами и подвергнутого ТОО образцов (кривые 1 и 2 соответственно) также имеют похожую тонкую структуру с бесфонными линиями при $1.638 \mathrm{eV}$. Обращает на себя внимание также то, что точно такие же излучательные переходы были обнаружены в [11] у кристаллов $\alpha-\mathrm{Al}_{2} \mathrm{O}_{3}$, облученных нейтронами флюенсом $10^{18} \mathrm{n} / \mathrm{cm}^{2}$.

Таким образом, полученные результаты показывают возможность нерадиационного создания в решетке $\alpha-\mathrm{Al}_{2} \mathrm{O}_{3}$ термически более устойчивых по сравнению с образованными нейтронным облучением и идентичных им по электронным свойствам сложных ЦО, активных в ближней ИК-области оптического спектра, что крайне важно при

Письма в ЖТФ, 2018, том 44, вып. 22 
разработке элементов силовой оптики. Результаты этой работы расширяют представления о природе и свойствах сложных дефектов, люминесцирующих в ближней ИК-области, а способ их создания, не связанный с дорогостоящими и небезопасными радиационными технологиями, может быть полезен при создании элементов памяти и различных оптических устройств на основе кристаллов $\alpha-\mathrm{Al}_{2} \mathrm{O}_{3}$.

\section{Список литературы}

[1] Dobrovinskaya E.R., Lytvynov L.A., Pishchik V. Sapphire: material, manufacturing, applications. N.Y.: Springer, 2009. $481 \mathrm{p}$.

[2] Аполлонов В.В. // Квантовая электроника. 2014. Т. 44. № 2. С. 102-121.

[3] Evans B.D. // J. Nucl. Mater. 1995. V. 219. P. 202-223.

[4] Сюрдо А.И., Кортов В.С., Мильман И.И. // Письма в ЖТФ. 1985. Т. 11. B. 15. C. $943-947$.

[5] Atobe K., Nishimoto N., Nakagava M. // Phys. Status Solidi A. 1985. V. 89. P. $155-162$.

[6] Zirour H., Izerrouken M., Sari A. // Nucl. Instrum. Meth. Phys. Res. B. 2016. V. 377. P. 105-111.

[7] Akiyoshi M., Takagi I., Yoshiie T., Qiu X., Sato K., Yano T. // Energy Procedia. 2015. V. 71. P. $320-327$.

[8] Rahman A.Z.M.S., Cao X., Wei L., Wang B., Ji H., Yang T., Xu Q., Atobe K. // Phil. Mag. Lett. 2014. V. 94. P. 211-216.

[9] Martynovich E.F., Tokarev A.G., Grigorov V.A. // Opt. Commun. 1985. V. 53. P. 254-256.

[10] Войтович А.П., Гринкевич В.Э., Калинов В.С., Кононов В.А., Михнов С.А. // Квантовая электроника. 1988. Т. 15. № 2. С. 318-320.

[11] Springis M.J., Valbis J.A. // Phys. Status Solidi B. 1985. V. 132. P. K61-K65.

[12] Лазарева Н.Л., Ракевич А.Л., Мартынович Е.Ф. // Фундаментальные исследования. Физ.-мат. науки (Иркут. ун-т). 2015. № 2. С. 2585-2589.

[13] Соловьев С.В., Мильман И.И., Сюрдо А.И. // ФТТ. 2012. Т. 54. В. 4. Р. 683690.

[14] Surdo A.I., Vlasov M.I., Milman I.I. // Rad. Meas. 2016. V. 90. P. 90-103.

[15] Raj S.S., Gupta S.K., Pathak N., Grover V., Tyagi A.K. // Adv. Powder Technol. 2017. V. 28. P. $1505-1510$.

[16] Tale I., Piters T.M., Barboza-Flores R., Peres-Salas R., Aceves R., Springis M. // Rad. Prot. Dosim. 1996. V. 65. P. 235-238. 